\title{
The landscape of PreK-12 engineering online resources for teachers: global trends
}

\author{
Aikaterini Bagiati ${ }^{1 *}$, So Yoon Yoon ${ }^{2}$, Demetra Evangelou ${ }^{3}$, Alejandra Magana ${ }^{4}$, Garene Kaloustian ${ }^{5}$ and Jiabin Zhu $^{6}$
}

\begin{abstract}
Background: The newly formed discipline of engineering education is addressing the need to (a) enhance STEM education for precollege students and (b) identify optimum ways to introduce engineering content starting, perhaps, from the early ages. Introducing engineering at the Prekindergarten through 12th grade (PreK-12) education level requires significant changes in teacher preparation and support. It highlights the need for developing developmentally appropriate content knowledge and pedagogical methods, thus revealing the challenges of preparing teachers to incorporate this type of knowledge base into their practice. Although professional development offered by universities, school districts, and other educational entities provides the primary source of formal learning tools for teachers, an increasing number of teachers also utilize other informal web-based resources regularly. This paper examines available Prek-12 engineering web resources offered by entities formally related to education in seven different languages, namely Arabic, Chinese (Mandarin), English, French, Greek, Korean, and Spanish.
\end{abstract}

Results: Findings showed how different educational systems designated different attention to the entry level ages when introducing engineering content. Differences in the terminology used to identify STEM resources for introducing these topics also became apparent. Similarities suggest that a large number of resources available on the web were originating in all researched languages. However, the developmental appropriateness and content validity of many of these resources remained questionable in many cases. In general, there was a plethora of isolated activities and lesson plans but significantly fewer complete engineering curricula available to teachers on the web.

Conclusions: This study presents a comparative analysis of the international landscape of PreK-12 engineering education and provides guidelines and samples of state-of-the art resources in each language for teachers interested in introducing their students to engineering as a reliable starting point towards PreK-12 engineering information gathering.

Keywords: PreK-12 STEM; PreK-12 engineering; Open web resources; Open educational resources teacher preparation; International comparison; Early engineering

\section{Background}

The technological challenges of our world affect every aspect of our social, cultural, and economic structures (Campos et al. 2000; Punie 2012) while modern governance adopts the position that 'science, technology, engineering, and math (STEM) disciplines are the drivers of technological advancement, innovation and foundational infrastructure that leads to secure economic future' (Watt et al. 2007, p. 759). Understanding that STEM, technology and engineering in particular, can be critical to a country's welfare (Sanders 2009), the development of human capital in

\footnotetext{
* Correspondence: abagiati@mit.edu

${ }^{1}$ MIT-SUTD Collaboration Office, Massachusetts Institute of Technology, Cambridge, MA, 02139, USA

Full list of author information is available at the end of the article
}

the STEM fields presents a major challenge as recent trends point to a diminishing interest in these fields (Kuenzi 2008; Becker 2010; Dimopoulos et al. 2011). Success will be measured by our ability to reverse the trend, through the transformation of the educational processes in fundamental ways (Campos et al. 2000; Punie 2012).

A head start for the advancement of STEM education has lead scholars to the study of curricular ideas prior to college (Bagiati and Evangelou 2008; Brophy et al. 2008; Bagiati 2011) not only because of the long preparation necessary for success in the STEM fields but also to address student motivation in a timely manner. Student motivation, which needs to be fostered in the early childhood years, has emerged as an important influencing factor for attracting students to engineering domains 
(Graziano et al. 2012). Given these trends, many institutions are now providing open educational resources (OER) specifically tied to STEM, and sometimes to engineering in particular.

This drive for open access web resources comes at a time of generalized interest in Prekindergarten through 12th grade (PreK-12) STEM education in many countries aiding the development of the new content. Scholars now seek to understand and enhance the ways PreK-12 teachers are advancing their education and identifying optimum ways to introduce engineering in their classrooms (Brophy et al. 2008; Katehi et al. 2009; National Research Council 2009; Moore 2010; Bagiati 2011; Wang et al. 2011; Bagiati and Evangelou (in press(a); Bagiati and Evangelou (in press (b)). Introducing engineering at the PreK-12 level, however, reveals a need for a deep understanding of the content and methods that are also developmentally appropriate at each grade level (Bagiati and Evangelou 2008; Bagiati 2011; Bybee 2011). To complement this effort, scholars are seeking to understand how teachers prepare to incorporate this new content into practice (Shulman 1986; Bagiati and Evangelou 2008; Wang et al. 2011; Bagiati and Evangelou (in press (a)).

In many countries, ministries of education, universities, school districts, and various other educational entities responsible for offering formal teacher education and on-going professional development support teachers in remaining current in their expertise. Teachers now also utilize a variety of other ways to stay current and informed as professionals (Bagiati et.al. 2010), including peer-topeer (Lock 2006; Borko et al. 2009) or individual efforts to (a) enhance their skills by investigating new content and to (b) access, comprehend, incorporate, and adopt new practices. Teachers use the Internet more than books or journals in order to understand new concepts and to find curricula or small-scale activities to incorporate into their teaching (Hedtke et al. 2001; Recker 2006).

This approach is gaining popularity with teachers worldwide irrespective of the diversity of educational systems, norms, and practices, as it allows teachers to balance preparation with job and family commitments (Borko et al. 2009; American Association of Colleges for Teacher Education 2013). Information and communication technologies appear to 'provide more flexible and effective ways' for teachers to prepare and remain updated (Jung 2005, p. 94) while at the same time allowing them the opportunity to expand and connect to the global teacher community. In this new context, the access to open web-based educational resources is despite the challenge of searching and verifying online learning resources ascertaining the quality and validity of the material. Many educators limit their information seeking primarily within search engines and do not take full advantage of educational-related digital libraries (Perrault 2007). Teachers' expectations in screening educational resources include quality of the resource, as well as additional contextual information beyond that resource (Recker et al. 2004); specifically characteristics, such as age-appropriateness, accuracy, and contemporariness (Recker et al. 2004). Accessing and screening open web resources on PreK-12 engineering education present additional barriers including factors, such as content validity, accessibility, and language.

\section{Content validity}

In recent years, 'teaching is becoming one of the most challenging professions in our society where knowledge is expanding rapidly' (Jung 2005, p.94). Having extensive experience with in-service PreK-12 teachers, we are aware of the difficulties when attempting to identify valid engineering-related curricula online. Teachers, especially at the early education level, usually do not receive formal exposure or preparation for the implementation of engineering in class (Bagiati and Evangelou (in press (a)). STEM content, particularly engineering content, is considered a very challenging topic for teachers to conceive and successfully implement in class. For STEM education in particular, concepts, such as engineering, technology, and design, are easily misunderstood and misrepresented in class (Yaşar et al. 2006; Hsu et al. 2011; Bairaktarova et al. 2012). This makes it even harder for them to understand the need and become able to identify and evaluate the appropriateness of resources among the uncategorized plethora of information to be found on the web.

Prior small-scale research studies on the topic (Bagiati et al. 2010, 2011) have shown an adequate number of resources on PreK-12 engineering curricula, lesson plans, and activities available on the web. However, these studies have shown that the pedagogical and content reliability of such resources are limited. Elementary and early engineering education is still at its infancy (Bagiati et al. 2010; Bagiati 2011), and content validation is difficult to distinguish within the currently available content, even to engineering education specialists. The existing content is either addressed directly as engineering or gets introduced within an integrated STEM context. However, when discussing the educational level that the PreK-12 websites are targeting, things appear so far to be uneven. The majority of websites only offer educational resources for older grade level audiences, such as high school or middle school students.

\section{Accessibility}

Open educational resources (OER) are supported by UNESCO, and many countries support this idea (Johnstone 2005) by offering a wide variety of OER. However, the Internet governance and Internet freedom policies set by individual governments, are sometimes causing access to these resources to be limited or making OER 
completely unavailable within a country. Restrictions on accessibility might not always be applied to the content of the resources per se but they may apply to the software platform that the developers have chosen in order to share content. Furthermore, educational entities developing educational content suggest user regulations that may cause accessibility issues as well. Additional challenges to accessing OER may be encountered as a direct result of insufficient technology infrastructure.

\section{Language barrier}

Up to date, the vast majority of the Internet content is in English (Gounari 2009, p. 170; Pimienta et al. 2009), and even though the development of web content in languages other than English is rising, 'the dominance of the English language unavoidably affects access for nonEnglish speakers. At the same time, those non-English sites are mostly limited to speakers of the specific language-a linguistic reality that compromises the "globality of the medium"' (Gounari 2009, p. 170).

Advancement in the development of online translation software has partially addressed this challenge and will continue to do so to virtually eliminating the linguistic barrier among users. However, a more persistent issue of access comes from the variety of disciplinary terms used in local education nomenclature (e.g., engineering vs. technology, design, or STEM).

In the English context, in certain European countries as well as in the United States, the English acronym STEM is popularly used to describe courses or educational content integrating science, technology, engineering, and mathematics within a PreK-12 educational curriculum (Sanders 2009). In recent years, there are additional efforts to highlight the $E$ in PreK-12 STEM education (Sanders 2009). The term engineering education was found to also be widely used, however, mainly at the college level in order to describe the wider concept of undergraduate or graduate studies within a school of engineering, and not so much, if at all, to describe PreK-12 content or practices. Furthermore, terminology, such as STEM education or engineering education, is not the norm in many educational systems around the world (e.g., in European countries, such as Spain, France, and Greece, in Arab-speaking countries, and in Asian countries, such as China and South Korea), where terms, such as invention education, creativity education, or technology education, are used in a broader sense to describe the same content. As an example, the education system of France is going through a transformation on how to perceive PreK-12 science, math, and technology education with implications on how material and resources are provided for the public schools, teachers, and other professionals. The emphasis has shifted from teaching content per se to skills that children should acquire at each grade level. Thus, the terms 'investigation' and 'inquiry' are critical within the web search for more specific content, namely science. Within a contemporary transformation of terminology in the field of Science, incorporating skill-based terminology, such as inquiry and investigation with its many variations and epistemological, psychological, and/or educational meaning, has led to a more hands-on approach to the field as a whole (Giordan 2010). Lebeaume (2011) highlights that the proposed amendments of the French education system (content-based teaching/learning to skill-based teaching/ learning) 'breaks down barriers between strictly disciplinary teachings since this deems unproductive for investment of educational achievements as a whole' (p. 2).

Our short exposure to the variations of approaches, regulations, and nomenclature shows how the global landscape of PreK-12 engineering web resources is considerably uneven for teachers to explore.

\section{Purpose of the study}

A scientific discipline is characterized by shared terminology negotiated and established in order to facilitate communication among scholars. In the newly formed discipline of engineering education, this process is on-going and acknowledges and respects existing nomenclatures across different cultures and educational systems. This paper aims to compare the international landscape on PreK-12 engineering education. We identified engineering educational websites constructed by credible organizations formally related to education, examined types of engineering education resources by grade level, and explored differences in the terminology to search engineering-related educational resources across seven languages; namely, Arabic, Chinese (Mandarin), English, French, Greek, Korean, and Spanish.

Additionally, we have placed a particular interest in identifying resources targeting early education. Resources targeting early education have a value of developmental nature attached to them. Moreover, they have a particular strategic significance, as the existence and quality of such resources reveal how soon different countries approach introduction to engineering and the importance that they place on this first introduction. Existing infant and toddler curricula designed to date follow a comprehensive approach to assist children development, and more specifically, to assist development of approaches to learning, social, emotional, and physical development, communication, and development of gross and fine motor skills (Copple and Bredekamp 2009). Although development in all aforementioned areas is essential for the child to be able to then successfully develop STEM thinking and learning, and while children play at this age can be considered precursor to engineering thinking and acting (Brophy and Evangelou 2007, Bagiati and Evangelou (in press (b)), the infant and toddler curricula are not designed to target STEM or engineering in particular. To date, the first 
curricula designed to specifically target STEM, design, and engineering are starting at the PreK level. Therefore, in order for our study to follow the most holistic approach while investigating engineering curricula, we chose to start our investigation at the Prekindergarten level.

The research questions guiding this study are as follows:

(a) What is the number of websites containing resources related to PreK-12 engineering-relevant content developed by entities formally related to education?

(b)Which percentage of the identified websites addresses early education?

(c) What is the curricular scope of the resources developed?

(d)What terminology in each of the represented languages is used to identify PreK-12 engineering related content?

(e) Are the resources identified openly accessible to teachers?

We believe that this study will (a) help future engineering content developers better understand their global audience and (b) help PreK-12 teachers in their attempt to self-educate and introduce engineering education in their schools. Furthermore, we expect research findings to enhance global discourse in regards to adaptation and implementation of the PreK-12 engineering content.

\section{Methods}

\section{Cross-cultural collaboration}

Researchers participating in this study had to comply with three fundamental criteria: (a) be native speakers of one language examined in the study, (b) be familiar with the discipline of engineering education and educational research, and (c) have personal experiences of a PreK-12 educational system of the language under examination. These criteria were adopted based on our understanding that 'among different educational systems, and according to different educational/technological cultures, similar content might be presented using varied terminology' (Lock 2006, p.2). All researchers but one were involved with the discipline of engineering education in the United States and all are graduates of different schooling systems located in Asia, Europe, Latin America, and the Middle East. Furthermore, two researchers are experts in the field of early education and child development.

The seven languages examined in this study cover a large portion of the Internet users. Figure 1 presents the countries around the globe where the seven languages are being used in the formal education system.

As of 2011, as presented in Table 1, all languages, except Greek, were listed among the top languages used on the Internet. More than $67.1 \%$ of the world Internet users and $55.8 \%$ of the world population use the seven languages that were explored. Approximately, $30.3 \%$ of the world population has access to the Internet. Among the seven languages, Korean speakers had the most Internet users $(55.2 \%)$ of the language population, followed by English (43.4\%) and Spanish (39.0\%).

Taking a look at the languages spoken around the world, we see that in the United States where the predominant language is English, a big segment of the population is also fluent in Spanish or another language. English is also used in many Caribbean, Asian, and African countries. In Canada, in addition to English, French is also used. Around the world, there are more than 30 francophone countries, while Spanish is the official language in 20 countries and spoken in many more. In the case of Europe, the European Union (EU) strongly encourages mobility among people of different EU countries, and in many countries, people speak more than their native language. On the same time, Chinese has attracted a lot of interest in recent decade and the number of people learning one of the major dialects is expanding. In conclusion, more and more people are now able to explore resources developed in languages other than their own, so teachers residing in countries other than the ones highlighted in Figure 1 may also use the languages explored.

\section{Procedures}

Each researcher collected and analyzed his/her own data based on a commonly designed procedure. Data were analyzed in light of an international comparison. Based on previous findings (Bagiati et.al. 2011) and given the complexity of the nature of the present study, the following procedure was put in place for the data collection and analysis. In order to establish a common scheme for the collection and analysis, individual researchers brought their extensive knowledge of their educational system and their understanding of OER to the discussion. Definitions were agreed upon and a common analysis plan was designed. When all analyses were completed, crosschecking of the results occurred in the cases that knowledge of each other's native language allowed for it, and data and reports were examined across languages.

\section{Data collection}

Initial data collection took place in spring of 2014 and updated most recently in August 2014. Researchers conducted a systematic Internet search through the Google and Yahoo search engines, using the keywords, PreK-12 engineering curriculum, and proceeded using the combination of keywords, including engineering curriculum, prekindergarten, kindergarten, elementary, middle school, high school, and PreK-12 in their own language. Following the initial exploration, modifications in the search terms were inevitable from language to language, given 


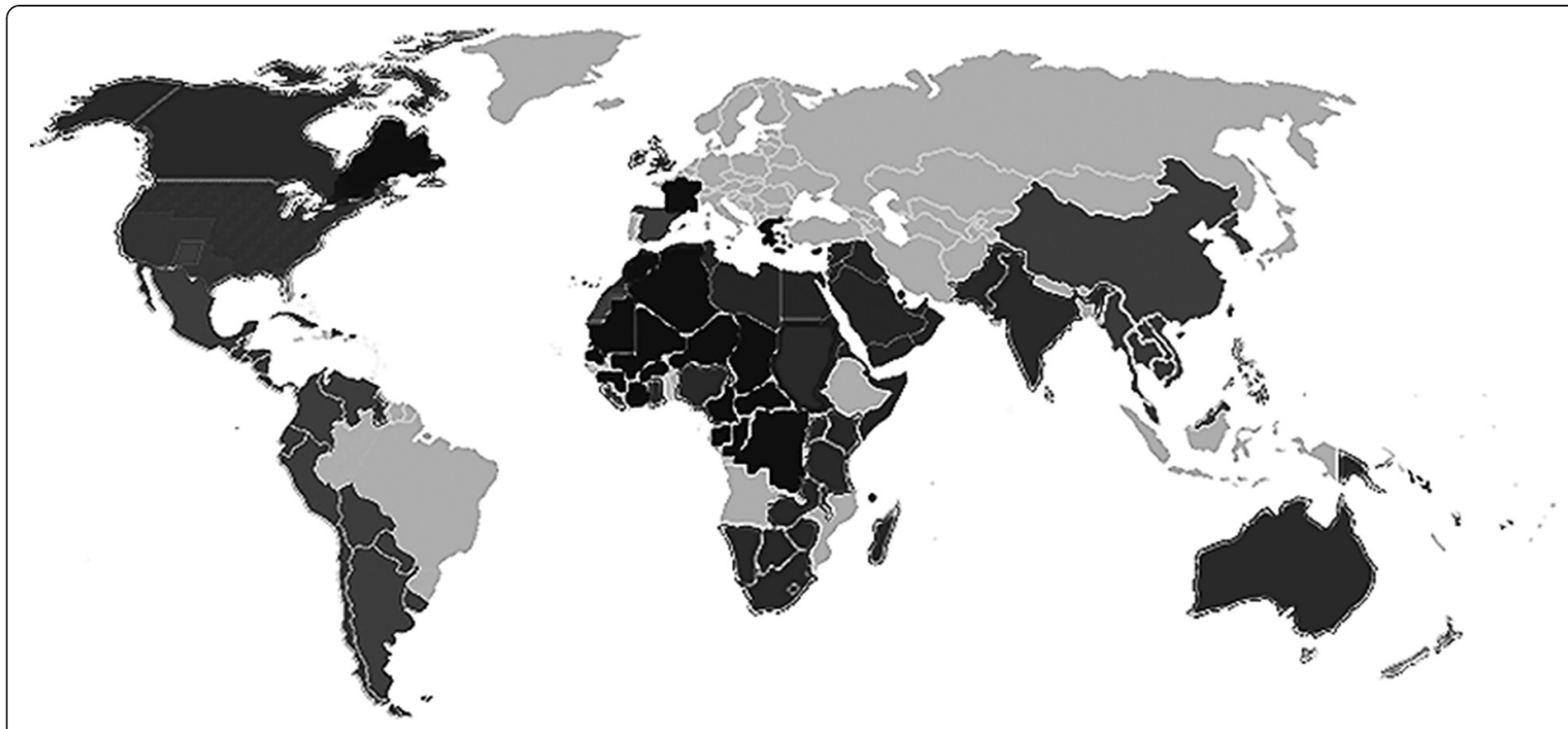

Figure 1 Countries around the globe where the seven languages are being used in the formal education system. Dark shades representing the countries that use Arabic, Chinese (Mandarin), English, French, Greek, Korean, and Spanish as one of the main languages.

the variation in STEM terminology used across the different languages/contexts.

In a second round of discussions of preliminary findings, key terms that resulted in relevant outcomes were shared, namely in educational resources that reflect engineering content. Subsequently, non-English speaking researchers used additional keywords, such as science, technology, design, creativity, and innovation, as the researchers expected that these words would lead them to the desired websites in some cultures. Table 2 presents all terms used from the research group in order to complete the search. The right column presents the terms that returned desired results in each language case.

The following variables on each website containing engineering content were collected.

- Title: The title of the website

- URL: The website URL

- Entity: Type of organization that provides engineering content

Table 1 Estimates of the top ten languages in the Internet (as of 2011)

\begin{tabular}{|c|c|c|c|c|c|}
\hline & $\begin{array}{l}\text { Top ten languages } \\
\text { in the Internet }\end{array}$ & $\begin{array}{l}\text { Internet users } \\
\text { by language }\end{array}$ & $\begin{array}{l}\text { Internet users } \\
\text { (\% of total) }\end{array}$ & World population & Internet accessibility (\%) \\
\hline & English & $565,004,126$ & $26.8 \%$ & $1,302,275,670$ & 43.4 \\
\hline & Chinese & $509,965,013$ & $24.2 \%$ & $1,372,226,042$ & 37.2 \\
\hline & Spanish & $164,968,742$ & $7.8 \%$ & $423,085,806$ & 39.0 \\
\hline & Japanese & $99,182,000$ & $4.7 \%$ & $126,475,664$ & 78.4 \\
\hline & Portuguese & $82,586,600$ & $3.9 \%$ & $253,947,594$ & 32.5 \\
\hline & German & $75,422,674$ & $3.6 \%$ & $94,842,656$ & 79.5 \\
\hline & Arabic & $65,365,400$ & $3.3 \%$ & $347,002,991$ & 18.8 \\
\hline & French & $59,779,525$ & $3.0 \%$ & $347,932,305$ & 17.2 \\
\hline & Russian & $59,700,000$ & $3.0 \%$ & $139,390,205$ & 42.8 \\
\hline & Korean & $39,440,000$ & $2.0 \%$ & $71,393,343$ & 55.2 \\
\hline Top ten languages & & $1,615,957,333$ & $82.2 \%$ & $4,442,056,069$ & 36.4 \\
\hline Rest of the languages & & $350,557,483$ & $17.8 \%$ & $2,403,553,891$ & 14.6 \\
\hline World total & & $2,099,926,965$ & $100.0 \%$ & $6,930,055,154$ & 30.3 \\
\hline Total of six languages & & $1,404,522,806$ & $67.10 \%$ & $3,863,916,157$ & 36.3 \\
\hline
\end{tabular}

Languages in italics are the languages examined in this paper. Source: Internal World Stats: Usage and Population Statistics. Retrieved from http://www.internetworldstats.com/stats7.htm. 
Table 2 Searched keywords related to PreK-12 engineering education web resources

\begin{tabular}{|c|c|c|}
\hline Language & Terms that did not work & Terms that worked \\
\hline Arabic & Engineering, activities, projects & 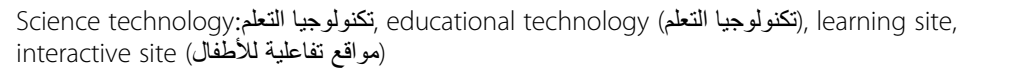 \\
\hline Chinese & $\begin{array}{l}\text { Engineering education, Engineers' education, } \\
\text { middle/high school, kindergarten }\end{array}$ & $\begin{array}{l}\text { Science education (科学教育), science and technology education (科学技术教育), } \\
\text { youngsters (青少年), child (儿童/幼儿), science and technology museums (科技馆), } \\
\text { science popularization (科普), work and technological education (劳动技术教育), } \\
\text { practicality (实践能力) }\end{array}$ \\
\hline English & Creativity, innovation, invention & K-12, engineering, science, technology, STEM, design, curriculum \\
\hline French & Engineering education & $\begin{array}{l}\text { Ingenieur (engineer), ressource pedagogiques pour l'ingenieur préscolaire (educational } \\
\text { resources for the preschool engineer), science (science), ministere de l'education, } \\
\text { technologie (technology), enseignement préscolaire (preschool education/teaching), } \\
\text { ateliers scientifiques (scientific workshop), musee scientifiques (scientific museum), } \\
\text { sciences a l'ecole (science at school), sites scolaires de sciences et technologie } \\
\text { (academic sites for science and technology), resources academiques (academic resources), } \\
\text { culture scientifique ou technologique (scientific or technologic culture), sites nationales de } \\
\text { sciences et de technologie (National sites of science and technology), projets scientifiques } \\
\text { (scientific projects), projets de sciences (science projects), exposciences (science exposition) }\end{array}$ \\
\hline Greek & $\begin{array}{l}\text { Engineering education, PreK-12 innovation, } \\
\text { invention }\end{array}$ & 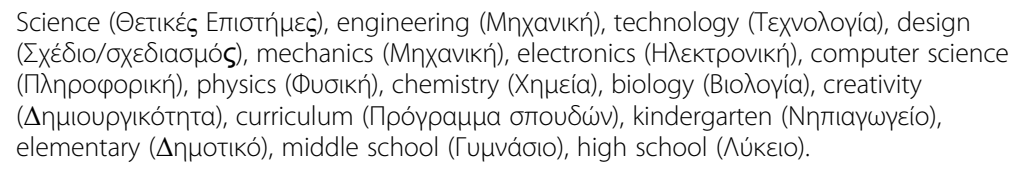 \\
\hline Korean & PreK-12 engineering education & $\begin{array}{l}\text { Engineering (공학), science education (과학교육), STEAM, STEM, science education } \\
\text { (과학교육), technology education (기술교육), block building (쌓기), machines (기 계), } \\
\text { tools (도구), invention (발명), creativity (창조), pre-engineering education (예비공학교육), } \\
\text { STEAM (science, technology, engineering, arts, and mathematics) integrated education } \\
\text { (융합인재교육) }\end{array}$ \\
\hline Spanish & Engineering education, curriculum & $\begin{array}{l}\text { Science and technology museums (Museos de Ciencia y Tecnologia), science projects } \\
\text { (Proyectos de Ciencia), school technology projects (Proyectos Escolares de Tecnologia), } \\
\text { engineering school projects (Proyectos Escolares de Ingenieria), didactic materials for } \\
\text { technology education (Materiales Didacticos en Educacion en Tecnologia), didactic } \\
\text { materials for engineering education (Materiales Didacticos para Educacion en Ingenieria), } \\
\text { engineering activities for elementary education (Actividades de Ingenieria para Educacion } \\
\text { Primaria), engineering experiments (Experimentos de Ingenieria), engineering projects for } \\
\text { children (Proyectos de Ingenieria para Ninos). }\end{array}$ \\
\hline
\end{tabular}

- Education level: Target students' age or grade level for the content

- Terms: Terms related to STEM used by the developers while introducing the content in the web resources

- PreK-3 and grades 4 to 12 resources: Type of content presented on the website, namely single activities, learning plans, or full curricula in grades PreK-3 and grades 4 to 12 .

Previous studies have shown that although many websites claim to present PreK-12 content, they typically only target older students, while web resources for the early education students are very limited or absent (Bagiati et.al. 2010; Bagiati et.al. 2011). Content was carefully examined to ascertain which websites actually made available content targeting early ages and to identify such relevant content.

In many cases, the Internet searches led to websites that were portals redirecting users to other websites containing the desired educational content. Furthermore, although many websites claimed to contain curricula, they included individual lesson plans or scattered activities. Therefore, researchers recorded the content of each website's homepage and examined the actual type of content presented. As many web searches led to websites that served as portals to other sites containing the actual educational material, the researchers kept track of the existing portals but did not add them to the final data set for analysis. In addition, many websites that appeared through the searches only contained information regarding engineering outreach programs, while others were websites not openly presenting but selling the desired educational resources. Commercial websites and websites presenting outreach programs, without presenting any educational resources, were also not included in the study.

The engineering resources identified were classified as: (a) activity, small scale, stand-alone, designed for use in or out of class, and not presenting any particular learning objectives or assessment mechanism, (b) lesson plan, a structured process, typically outlining step-by-step instructions for teachers, including learning objectives accompanied by an assessment mechanism, or (c) curriculum, defined by Toombs and Tierney (1993) as 'an intentional design for learning negotiated by faculty in light of their 
specialized knowledge and in the context of social expectations and students' needs' (p. 183).

In order to enhance the validity of the search, our data sample was limited to web resources only offered by credible organizations, such as universities, museums, foundations, institutions, and similar entities formally recognized as relevant to engineering, as well as educational and curriculum topics. Furthermore, during our data collection, we paid careful attention in order to include websites that would present resources related to engineering concepts and the design process and to exclude STEM websites that were actually only addressing a traditional scientific discipline, e.g., only biology, chemistry, physics. Additional file 1 presents the complete data set of the websites that were analyzed.

At this point, it should be noted that data collection and analysis in this paper represents the OER available on the web in August 2014, we do understand though that due to the very nature of the Internet, many websites analyzed have probably updated their content by now.

\section{Data analyses}

Data analysis was performed using descriptive statistics, and data were summarized in graphs for frequency comparisons. Initially, we compared the number of web resources containing PreK-12 and PreK-3 engineering content. The following themes were identified: (a) types of organizations, (b) numbers of websites and type of content presented, and (c) accessibility. In Table 3, additional criteria on the quality of the resources according to understanding by design (Wiggins and McTighe 1997, 2005) are presented. Understanding by design is a way of thinking about curricular design and implementation that emphasizes three main components: (a) the content of the lesson including learning outcomes, credibility, or validity of the content, explanations of how to implement the content, and so on; (b) determining the acceptable evidence of learning including methods of assessing learning while providing formative feedback to learners or providing learners with an opportunity to reflect about their learning; and (c) the instructional approach or pedagogy considering aspects, such as teamwork, hands-on activities, inquiry learning, and design- or inquiry-based learning. We used understanding by design as a framework for this part of the study because it encompasses all elements that should be involved in any instructional intervention.

\section{Results}

Results are based on the factors that emerged throughout the data analyses to highlight differences or similarities across the seven languages. Considered factors include frequency of identified websites, types of entities that developed engineering educational resources, types of engineering contents by grade level, terms searched to
Table 3 Criteria used to establish validity of web resource for engineering education

\begin{tabular}{|c|c|}
\hline Topic to examine & Relevant questions to ask \\
\hline \multicolumn{2}{|l|}{ Regarding content: } \\
\hline & $\begin{array}{l}\text { - What are the credentials of the } \\
\text { author/sponsor of the site? }\end{array}$ \\
\hline & - How updated is the content? \\
\hline & $\begin{array}{l}\text { - Is there a feature that will allow } \\
\text { you to get your questions } \\
\text { answered such as a direct contact } \\
\text { for the developer or a discussion } \\
\text { forum? }\end{array}$ \\
\hline & $\begin{array}{l}\text { - Has the content presented ever } \\
\text { been implemented in a class and } \\
\text { if so what was the evaluation? }\end{array}$ \\
\hline & - Has the content been assessed? \\
\hline \multirow[t]{6}{*}{ Regarding instruction: } & Does it present \\
\hline & $\begin{array}{l}\text { - A curriculum (if not then lesson } \\
\text { plans...)? }\end{array}$ \\
\hline & - Clear learning objectives? \\
\hline & $\begin{array}{l}\text { - Clear instructions for implementation } \\
\text { in class? }\end{array}$ \\
\hline & $\begin{array}{l}\text { - Ways to assess student learning } \\
\text { during class or rubrics? }\end{array}$ \\
\hline & $\begin{array}{l}\text { - Tests/homework sample and } \\
\text { grading method? }\end{array}$ \\
\hline \multirow{7}{*}{$\begin{array}{l}\text { Regarding pedagogy appropriate } \\
\text { for engineering: }\end{array}$} & Does it allow opportunities for \\
\hline & $\begin{array}{l}\text { - Design based learning or project } \\
\text { based learning? }\end{array}$ \\
\hline & - Hands on activities? \\
\hline & - Individual as well as teamwork? \\
\hline & - Discussion and reflection? \\
\hline & - Student Feedback? \\
\hline & $\begin{array}{l}\text { - Presentation of the final product } \\
\text { to external audience? }\end{array}$ \\
\hline
\end{tabular}

identify engineering educational resources by language, and accessibility to the websites. Therefore, the results assisted us to better understand the global landscape of PreK-12 engineering education web resources and to start identifying global trends.

\section{Web resources}

The number of websites containing educational resources per language was identified first. Figure 2 shows a summary chart that compares the number of websites with OER that contain engineering content targeting PreK-12 and PreK-3 students. Figure 3 shows the percentage of PreK-3 websites with resources within the PreK-12 ones. Since each country using one of the languages has different infrastructure and accessibility regulations for the use of educational web resources, there are two underlying issues that need to be accounted for: first, even if there is no 


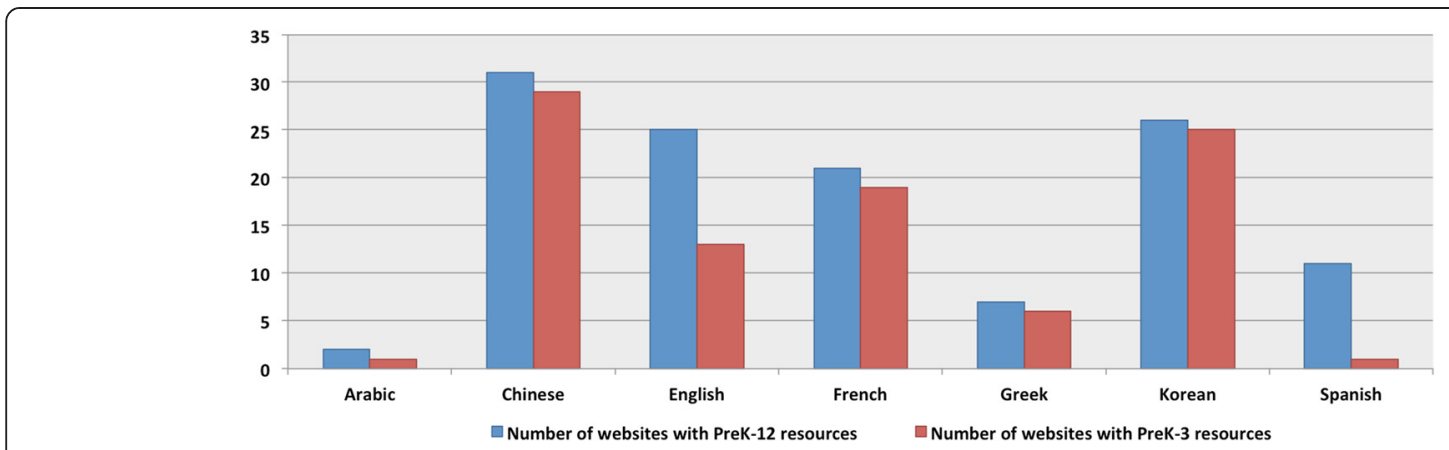

Figure 2 Number of websites presenting PreK-12 educational engineering resources identified per language.

language barrier, resources might still not be visible or accessible to the public or users out of a country. Second, different resources might have varied emphasis on each of the four components of PreK-12 STEM education, as well as on the ages they are targeting. Thus, there is a chance that the number of websites could be impacted by those conditions. Despite the disparity, results of this study provide insight into the contemporary landscape of engineering education for PreK-12 students in the countries using the corresponding languages.

\section{Entities developing PreK-12 engineering resources}

In Table 4, we present the entities, officially related to education, that appear to work towards development of PreK-12 engineering content. The identified entities were Ministries of Education, usually in collaboration with various government-related organizations, private organizations formally recognized to be related to educational content development, foundations, universities, teacher organizations, and museums. Furthermore, in Table 5, we present if these resources were open to all users or if there were restrictions that apply.

\section{Types of educational engineering content}

Taking a look at the type of PreK-12 contents developed by the aforementioned entities, curricula - learning resources that provide a lesson plan to help the teacher implement the activity in the classroom, and assessment instruments, so teachers can evaluate knowledge gain - were rare, if any, in all seven languages. As presented in Figure 4, individual, small-scale activities were the most common type of resource identified, followed by individual one- or two-session-long lesson plans. Among the seven languages, Arabic was the language in which websites with only activities were found. In the cases of Korean, Greek, and Spanish, in addition to individual activities, there were a few websites with lesson plans and one or two websites with curricula. Examining the other end of the spectrum, Chinese and English, followed by French, are the languages in which the largest numbers of websites with curricula have been developed. Similarly, as presented in Figure 5, the PreK-3 level resources are mainly comprised of individual activities, with rare lesson plans and even fewer curricula.

\section{Terminology}

Careful examination of the terms used in web searches and identification of PreK-12 engineering resources revealed that similar types of content were addressed in many different ways around the world. Table 2 presents the terms used by the researchers in order to identify the engineering educational resources. As expected, according to the nomenclature of the languages represented in this study, the web searches leading to the desired data had to include different terms.

As Table 2 indicates, in alignment with the plurality of the search terms, the terms used in the websites also vary among the different languages. The terms that appear in

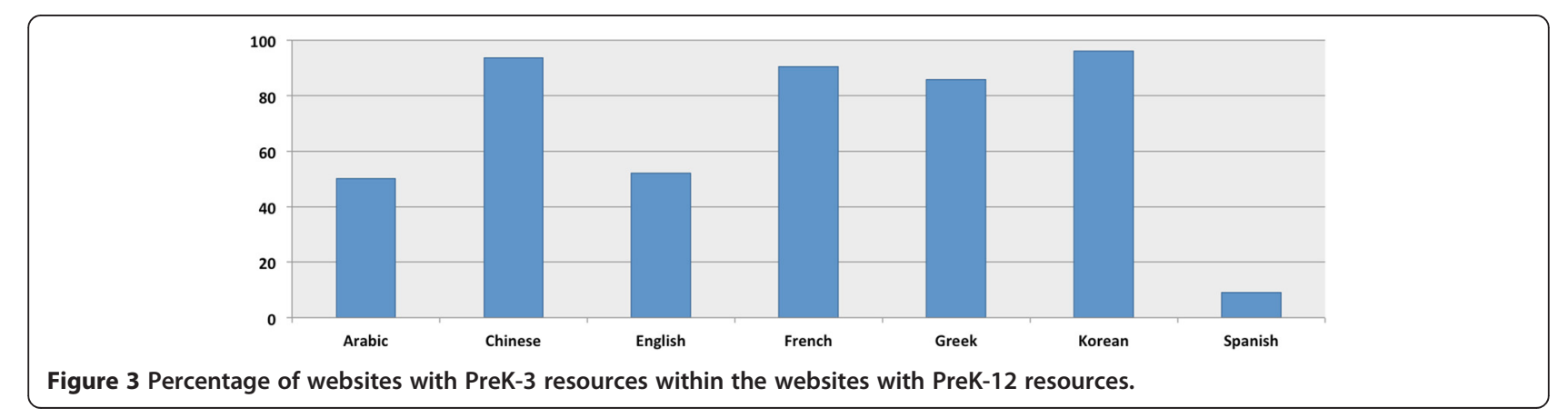


Table 4 Types of organizations (entities) that develop and distribute engineering web resources per language

\begin{tabular}{lllllll}
\hline Language & G & P & F & U & T & M \\
\hline Arabic & & $X$ & & & $X$ & \\
Chinese & $X$ & & & & $X$ & \\
English & $X$ & $X$ & $X$ & $X$ & $X$ & $X$ \\
French & $X$ & & & $X$ & & $X$ \\
Greek & $X$ & & $X$ & & & \\
Korean & $X$ & $X$ & $X$ & & & $X$ \\
Spanish & $X$ & $X$ & & & $X$ &
\end{tabular}

Note: $\mathrm{X}=$ exists; $\mathrm{G}=$ government organization/ministry of education; $\mathrm{P}=$ private organization formally related to education; $\mathrm{F}=$ foundation; $\mathrm{U}=$ university organization; $\mathrm{T}=$ organization by teachers; $\mathrm{M}=$ museum.

the websites are primary, Science, Technology, Engineering, and Mathematics, followed by STEM, Invention, Creativity, Design, and then Physics, Biology, Chemistry, Electrical, Mechanical, and Computer Science. As presented in Figure 6, the terms Science and Technology were commonly represented in all languages. The term Engineering appears mainly in English resources followed by Greek and Korean. We should note here that United States developers offered all English resources but one, which was British. The term STEM was, as expected, only used in the United States resources.

At the point of data collection for this study, engineering for P-12 education or P-12 engineering education rarely returned Korean web resources. Instead, pre-engineering education (예비공학교육) or science, technology, engineering, arts, and mathematics (STEAM) integrated education (융합인재교육) have started to appear to address integrated education across several disciplines that include engineering. In addition, many engineering activities have been conducted under the name of science education or programs for creativity and invention. The term Invention

Table 5 Accessibility and openness of the engineering education websites by language

\begin{tabular}{|c|c|}
\hline Language & Openness \\
\hline Arabic & All resources were open \\
\hline Chinese & $\begin{array}{l}\text { Most websites have resources readily available without } \\
\text { login process, } 6 / 31 \text { sites request login }\end{array}$ \\
\hline English & $\begin{array}{l}\text { Most websites have resources readily available without } \\
\text { login process, } 3 / 25 \text { sites request a free registration and } \\
\text { login }\end{array}$ \\
\hline French & $\begin{array}{l}\text { Most websites have resources readily available without } \\
\text { login process, } 1 / 21 \text { sites requests login }\end{array}$ \\
\hline Greek & All resources were open \\
\hline Korean & $\begin{array}{l}\text { Even though the use of web resources are free, most } \\
\text { websites require a free registration and a login process } \\
\text { to access the resources }\end{array}$ \\
\hline Spanish & $\begin{array}{l}\text { Most websites have resources readily available without } \\
\text { login process, } 3 / 11 \text { sites request login }\end{array}$ \\
\hline
\end{tabular}

was predominantly used in Chinese and it also appears in French and Korean web resources, and Creativity appears a few times in Greek and Korean websites. For Spanish, the terms Technology or Science and Technology were the most successful ones. Greek is also the language that, when it comes to the content distributed to the schools by the Ministry of Education, no aggregate terminology, such as STEM or Science, is used, and web resources are only categorized under the individual disciplinary descriptive terms of Design, Physics, Chemistry, Biology, Math, Electrical, Mechanical, and Computer Science. There was also one case in Arabic in which the content was also described as general information.

\section{Accessibility}

As a final factor, examining the open availability of these resources to teachers or other potential users made some discrepancies apparent. Discrepancies can be explained by the facts that different countries have adopted different standpoints in terms of (a) offering open resources and (b) allowing particular platforms supporting share of content to be accessible within their country.

\section{Discussion}

Findings are summarized into four main points below.

- Across all languages, web resources on learning materials about engineering were easy to locate. However, developmental appropriateness and content validity were hard to establish. Searching for such content requires painstaking attention.

- Web resources presenting scattered activities and lesson plans are well developed. Engineering curricula (e.g., containing additional resources, such as indications of pedagogical strategies and assessment instruments) are significantly fewer.

- The number and type of resources developed to first introduce early education students to engineering content differ significantly across languages.

- All languages revealed the availability of engineering content but different terminology was employed.

The search for web-based PreK-12 engineering curricula revealed a wide variety of resources developed by different education-related entities, as well as individuals and corporations. However, resources presenting valid engineering curricula were limited, and in some cases, they were particularly hard to identify among the plethora of information. The large variety of uncategorized and difficult to validate information may result in teachers being discouraged and confused when they attempt to familiarize themselves with engineering. Furthermore, the uneven distribution in regards to the language used to describe the content made the resources widely available to some 


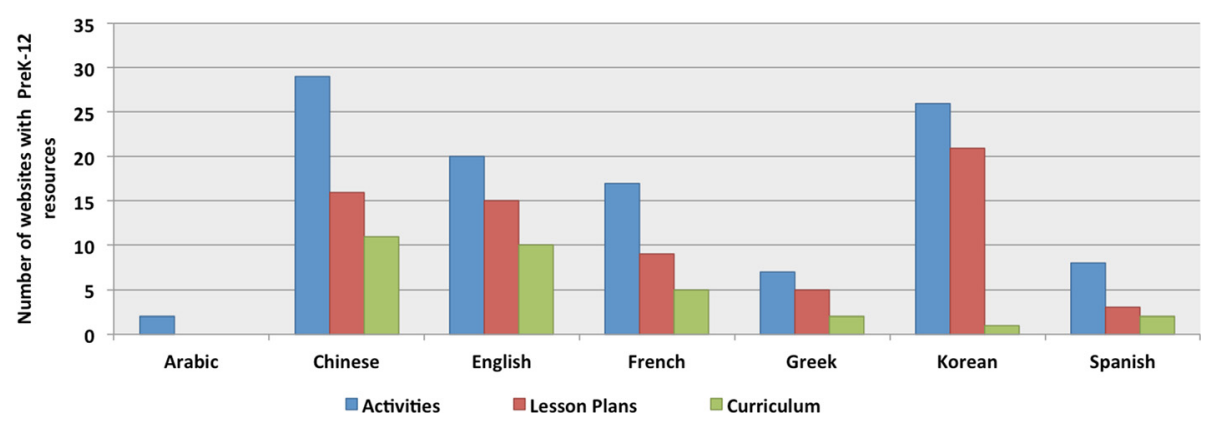

Figure 4 Number of websites presenting PreK-12 activities, lesson plans, and curricula per language.

target groups, while still a large number of teachers cannot take advantage of this shared information.

International findings regarding the type of content remained consistent with the group's prior research findings based on the English websites' analysis (Bagiati et.al. 2010). Most resources were comprised of individual activities, while well-organized lesson plans or long-term curricula were harder to find, if at all. For a PreK-12 teacher, identifying some engineering activities to bring in class is always a good first step. The lack of further instruction in regards to how to make visible and assess engineering-related learning, or how to proceed in a subsequent class in order to provide the students a more holistic experience, still leaves the teacher's preparation incomplete. However, the increasing level of global activities, the interactive nature of the Internet, and the global desire to share educational resources will surely be positive forces in improving the quality of available resources, thus facilitating teacher access and adaptation of engineering content in the PreK-12 engineering relevant education in schools.

Availability of early engineering web-based materials was uneven around the globe but well under way in multiple contexts, languages, and cultures. When considering early education of engineering, China appeared to be the country that has the most web resources regarding PreK-3 engineering resources, followed by Korean, French, and English-speaking countries. English web-resources appeared to have a strong presence in the PreK-12 level, but when comparing proportions within those websites for the PreK-3 alone, they appeared to be significantly less. In the case of Arabic-speaking countries, only two websites with OER were identified, and one of them also contained some PreK-3 STEM activities. In the case of Greece, it is particularly interesting that although there were not as many resources compared to other languages, all but one website included content targeting the PreK-3 group, probably indicating a particular value placed onto early education. Spanish was the language that showed a very weak presence of PreK-3 content among the seven languages.

Although the Internet allows for access to curricula developed and offered to a global audience, the terminology used in seven languages in which this content is presented appeared to be a barrier. Users start using the search engines by looking up for terms that represent their own educational nomenclature. A direct translation of these terms most probably would lead to a very small number of relevant entries. Different educational systems present similar educational content but employ different

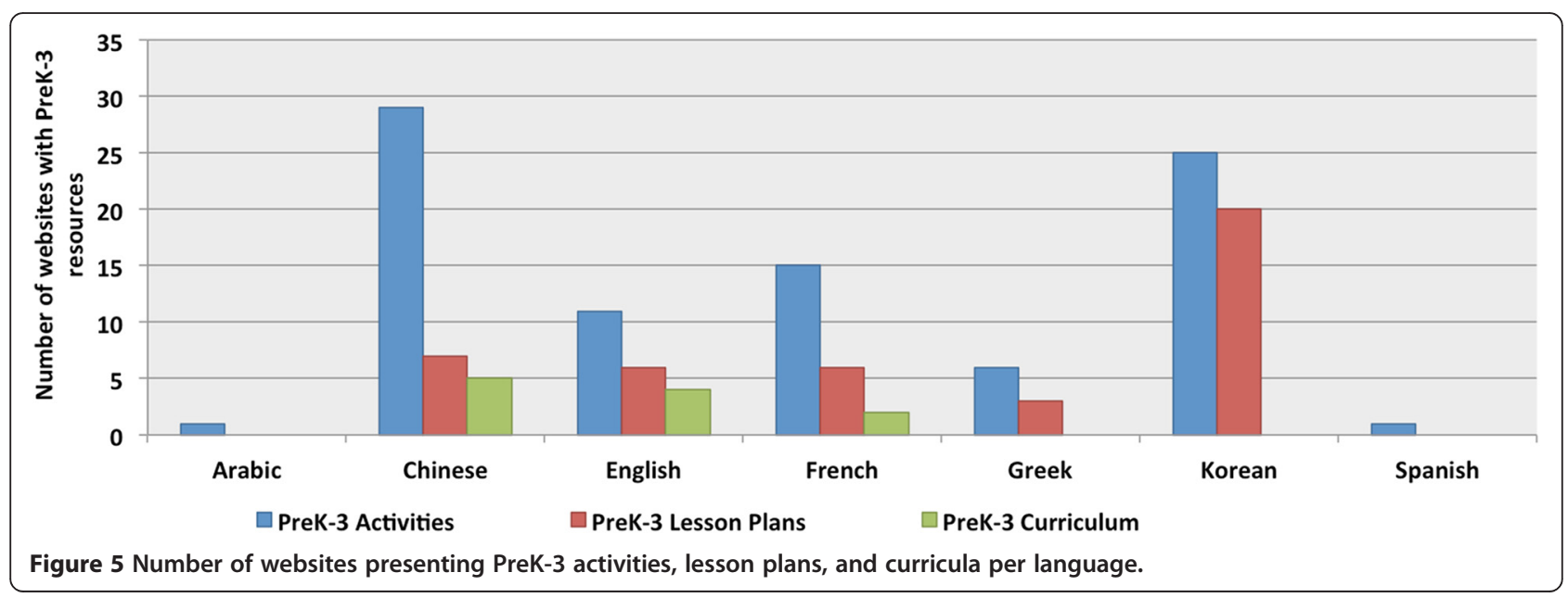




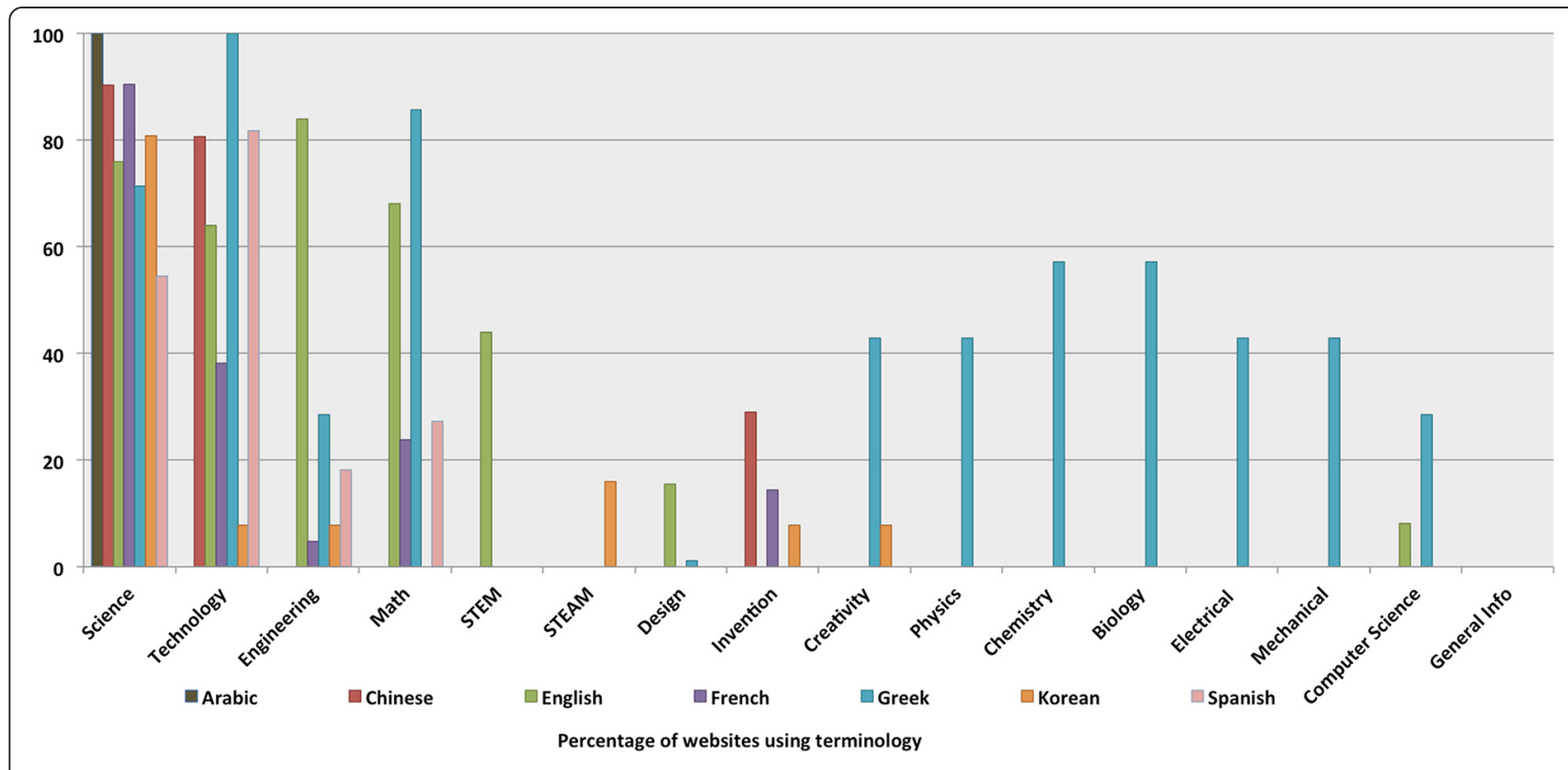

Figure 6 Percentages of websites using engineering-related terminology per language.

terminology, and although web translators are returning quite accurate results when it comes to direct translation, such differences in conceptual interpretations cannot be accurately represented yet. In the United States, the terms Engineering, STEM, and Science are the predominant ones. In Arab, European, and Latino cultures represented by Arabic, Greek, French, and Spanish, the labels of Science and Technology are used more often. Asian cultures using Chinese and Korean refer to similar content using terms such as Creativity and Invention.

Although it does not appear to be a serious issue, we also observed a small disparity in the availability of these types of resources across seven languages. Internet accessibility, and also different trends regarding content accessibility that appear to be the norm among different cultures and countries (open source content vs. content available for citizens only), may also influence the spread of the educational content. Therefore, for teachers to remain current or further promote their leaning, accessibility should be considered in the use of the Internet to openly distribute resources through individual professional initiatives.

\section{Implications for teaching}

Examining our resources within the framework presented in Table 3, researchers have selected the resources presented below as a sample that meets most criteria in every language. Quality PreK-3 resources have also been identified and are presented due to the group's particular interest in early education resources and due to the different developmentally appropriate pedagogies required for this age level. However, such content could not be identified in all languages. Taking into consideration the pace at which online content appears or changes daily, the audience is not suggested to consider the selected resources presented as the state-of-the-art contents at the time this paper is published or read but as a good example of a high-quality resource. We hope that teachers can easily use the criteria, presented in Table 3, for future references, as they will be attempting to evaluate content on their own.

\section{Arabic}

Regarding the Arabic websites, there were no comprehensive websites presenting curricula or even lesson plans. As presented in Figure 4 above, resources would present small-scale individual activities with no further information regarding assessment or evaluation of the content or the pedagogy used.

\section{Chinese}

To provide a starting point for the Chinese language, while noting that the term engineering was not used in this culture to describe the content, we suggest the website of the Shanghai Association for the Advancement of Science for Youths as an example to showcase our criteria in discerning a quality website presenting content related to engineering education. As noted in the website, the Shanghai Association for the Advancement of Science for Youths is a part of the Shanghai Science and Technology Association. The association's aim is to promote educational reform in Science education, by enhancing scientific attributes among youths, and their website includes a list of scientific and technological teaching materials, including curricula, lesson plans, and formal and informal 
activities. These materials are organized in different topics, such as, 'Learning Science by Doing,' 'Innovation and DIY in Science Education, etc. They also provide a forum for posting excellent examples in science teaching and scholarly papers which are geared toward the need of teachers in science and technology. Well-organized curriculum/ lesson plans/activities are found within the list of examples in science teaching. Scholarly papers offer ideas and suggestions to teachers regarding different aspects in science teaching, such as teachers' roles in guiding students' innovative scientific and technological innovation, creative thinking among youths, etc. Their website is open to general public without any requirement for registration or login process.

\section{English}

A great starting point while searching in English would be the resources developed and presented by the Museum of Science in Boston. Through their National Center for Technological Literacy website (http://legacy.mos.org/ nctl/k12_curricula.php), people can find information and resources regarding various K-12 programs and curricula related to engineering, such as Engineering is Elementary (EiE) or Engineering the Future (EtF), and more. The website presents various resources for teachers, students, and parents; instructional videos to facilitate and guide the teachers on how to implement the lessons and activities in class based on research studies conducted on the curricula. The full curricula though are not always available online are for free. Teach Engineering - Resources for K-12 (http://www.teachengineering.org) and Engineering Go for it! (http://www.egfi-k12.org) are two more website teachers can use in order to find validated K-12 content. However, as both sites contain few curricula but a very big number of lesson plans or individual activities targeting almost all student ages from upper elementary all the way to high school, not all resources are presented in the same way, or provide the same level of information and support to the teacher. Regarding the early education level, website presenting a developmentally appropriate early engineering curriculum is Puppeteering to Engineering (P2E) (http://puppetengineering.com). P2E is a semesterlong, age-appropriate design-based curriculum, designed by two of the researchers participating in the current study, aiming to achieve higher knowledge integration of STEM in the preschool classroom and is addressing the STEM integration, with primary emphasis on the engineering component. Twenty-four lessons comprising the curriculum are available online in PDF format, including instructions for classroom implementation and assessment. The curriculum has been implemented in a preschool classroom, and the evaluation is also presented online.

\section{French}

Sciences et Technologie - Lot http://pedagogie.ac-toulouse. fr/lotec/Sciences/SPIP/ website appears to be one of the most comprehensive web resources within the French websites researched. It targets early, middle and high school students, as well as teachers of all science professions (biology, archeology, physics, math, natural science, environmental science, and numerous others). It can also be a good resource for parents. This website promotes hands-on scientific investigation based on four main concepts: energy, planet Earth, living organism, and unity and diversity of the living organism. The site is quite interactive, consisting of videos, articles, interesting visuals for anyone accessing the website for information about the specified concepts - it should be noted that within each concept, under the broader concepts mentioned, there are more detailed resources under each component.

There are examples of lesson plans that are also supported with further complementary resources. Every example of lesson plan is presented in PDF format for each age group or cycle; there are sample lesson plans that include a detailed step-by-step elaboration on a particular scientific concept to include the objectives, expected outcomes for the particular age group, and certain strategies that can be used to elaborate learning of certain concepts. All can enjoy the site for free. Also, given that this is a governmental website, each focus area ties in the topic to an ongoing initiative or project that is happening in a particular region - this is open for all to be aware of the ongoing events in the country, encouraging all the viewers to be more active members of their environment, making learning more fun.

La main à la pate, http://lamap.inrp.fr// is another example of a comprehensive website that aims to develop inquiry-based science education in primary and lowersecondary schools, with a hands-on approach being the pedagogical principle. Launched in 1996, initiated by the Nobel Laureate in Physics, Georges Charpark, La main à la pate became a foundation for scientific cooperation in 2012 founded by the Académie des sciences, the Ecole normale supérieure (Paris), and the Ecole normale supérieure of Lyon. The La main à la pâte foundation pursues and develops the activities carried out in France and the rest of the world. The website is translated into six languages, English, German, Spanish, Chinese, Serbian, and Arabic. Taken from the website, there are nearly 400 class activities available online with ten educational projects that have been freely distributed to 55,000 teachers worldwide. This website has provided support in terms of resources engaging 160 middle schools in integrated science education projects. Their priorities include producing and disseminating pedagogical and scientific resources and contributing to the training of teachers and trainers. With their international cooperation around science education, 
they have scientists and industrialists in the development of science education.

\section{Greek}

Regarding the Greek language, the Digital School (DS)

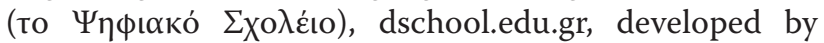
Greece's Ministry of Education, appears to be the main platform offering curricula and additional recourses. Greece is one of the countries that use national curricula. Teachers have to follow the curricula provided by the Ministry of Education, but can enhance their teaching with material of their choice as well. On the Digital School's website (http://digitalschool.minedu.gov.gr), teachers and students can find electronic books, curricula to be used at all classes and courses as well as additional resources that could be used to enhance a course, or links to other websites that may be helpful to teachers. When it comes to the early education level, no engineering curriculum is there to find. The Ministry of Education for this age level is offering some generic suggestions on how an early education teacher could introduce the use of a computer, other digital devises, and new technologies in the classroom.

\section{Korea}

When it comes to Korean, as Korea has a large proportion of the Internet users, various educational web resources were available. Particularly, each provincial office of education in Korea provides a website that contains all grade levels (K-12) of educational resources under the name of Education Supporting Center (ERC). As a quality example for a website, the KARI (Korea Aerospace Research Institute) school website (http://www.karischool.re.kr/) provides teachers with lesson plans appropriate for teaching elementary and middle school students. In detail, the website contains educational resources about four main topics related to aerospace engineering: aeronautics, rockets, space science, and space exploration. For each topic, a series of lesson plans consisting of three or four lesson plans, including various hands-on activities are prepared for elementary students and middle school students, respectively. All the lesson plans are presented in PDF files. Each lesson plan provides descriptions of the target grade level of students, lesson goals, and introduction and concepts for the topic, time estimates for each unit, materials for preparation, key vocabulary, instructions for activities, tips for teachers to deliver the lesson, worksheets for students that can be used for assessment, and reading materials. To use those resources, teachers need to create an account to login so that they can download the PDF documents.

Examining the early education space in Korean, in addition to the official websites by the government, private organizations run websites providing educational resources, specifically targeting young learners, in various subject areas that include engineering topics, too.
While educational resources for PreK and kindergarten were presented in the form of activities for the use of both parents and teachers, educational resources for early elementary students (grades 1 3) were better structured to be lessons and aligned well with the formal standards and curriculum of each grade level. Usually, engineering topics were presented under the name of science, creativity, or invention activities. Recently, the Korean Ministry of Education has adopted the term STEAM to initiate integrated education that embraces concepts across five subject areas, and STEAM education is becoming an integral part of K-12 education across the nation (Kim et al. 2013).

\section{Spanish}

An example in the Spanish language that meets the criteria presented in Table 3 is the website Exploradores (http://www.exploradores.org.pe), hosted by the National Society of Mining, Petroleum and Energy (Sociedad Nacional de Mineria Petroleo y Energia) in Lima, Peru. This website is organized in four related topics including mining, hydrocarbons, electricity, and environment. For each of these topics, several resources are provided targeting students and teachers. Resources for students include an interactive multimedia scene where students can explore its components through an interactive map. Each component of the scene provides a link to a sub-topic that provides additional information in the form of text, images, frequently asked questions, and additional related links to other websites. Additional resources available for both teachers and students are educational slides and downloadable and printable glossary of terms in the form of pictures and text.

Resources for teachers include lesson plans organized by grade levels (elementary and secondary education) and topic (energy, mining, hydrocarbons). The organization of the lesson plan follows a logical progression by first introducing the topic and associated relevant concepts and processes, and then transitions into applications. In addition, the lesson plan provides teachers with activities for students to do (e.g., hand-outs). These activities are organized in a series of steps and are accompanied with guidelines of pedagogical strategies and materials students will use. These hand-outs are meant to be used to prompt students to reflect and, at the same time, assess what they have learned. The lesson plan also provides extensive materials for teachers to do reflection and formative evaluation of their lesson implementation. The lesson plan concludes with a glossary of terms, list of references, and complementary readings.

\section{Limitations and future research}

While we attempted to investigate PreK-12 engineering resources for teachers around the world, the searched languages were limited to seven languages; thus, we could 
not identify the current status of online PreK-12 engineering resources available in other languages. Considering the population presenting academic work relevant to PreK-12 engineering education curricula in scholarly settings, there is expectation that more relevant content could be identified in northern European languages and probably others as well. Furthermore, even though we discussed differences in searching strategies for every language, there might be a sampling error in identification of the online resources because of the massive websites containing the keywords.

Acknowledging the fact that one language does not only represent one country (e.g., French is spoken in more than 30 countries), we have tried to identify resources and information regarding STEM or engineering standards in many countries. However content available on the Internet was heavily available only from a small number of countries. A local nomenclature or a different educational standpoint towards STEM in PreK-12 may exist in other countries, but resources were not available on the web and therefore it is not represented in this paper.

In addition to the language and terminology limitations, the group made the deliberate choice to examine content developed by entities formally associated with education and curriculum development, to establish a first level of validation regarding the content examined. Searching on the web, there appeared to be dozens, and in some languages even hundreds, of additional web resources developed by individuals (teachers, students, and professional engineers). Lack of credentials in many cases placed content validity and pedagogical appropriateness of the content under question and requires further inquiry.

When examining the content, our group was aiming to identify engineering-related resources. Given that in many languages these recourses were to find under different terminology, e.g., science or creativity, we were excluding the cases where activities would only refer to a traditional scientific discipline or were just referring to an arts and crafts project. However, we understand that since no firm boundaries exist, especially when discussing STEAM topics, results are reflecting the researchers' perceptions on whether an activity should be categorized as engineering.

Last but not least, by going through the resources identified, it is the group's first impression that not all resources are of the same quality or would have the same impact when used. Although data related to implementation and assessment of the identified resources would be a valuable validation mechanism, relevant data was not available for most of the websites identified.

\section{Conclusions}

Based on the aforementioned themes identified, we conclude that although the advent of the Internet has made educational content globally available, the barriers related to language, terminology, content validity, and accessibility are tough to overcome, and currently may significantly limit single language users and teachers from taking full advantage of available content. Realizing how challenging it is for a teacher, student, or parent to navigate through such a chaotic cloud of educational resources, this calls to the community of engineering education for the question of who or what could be an authoritative body legitimated to produce and disseminate this kind of material. What would be the appropriate process for this dissemination? Then, should it be at a national or international level? Should one or more entities be responsible for validation of content and pedagogy? Furthermore, while attempting to disseminate the existing information, would it even be appropriate to attempt to impose a dominant terminology in hopes of structuring the future of engineering-related curriculum development more efficient for a global audience to identify, or should we, as a global community of scholars, focus on exposing and embracing all different terminologies currently used?

On a more immediate tone, the implications of this study could relate to the creation of collections for engineering education resources specifically, and STEM education in general. We suggest that these collections should not only include the name of the resource and the audience but that such resources should include metadata or descriptors, such as associated learning outcomes, target audience, scope, and overall measures of quality of the identified resources, to help teachers and students better navigate during their search.

\section{Additional file}

Additional file 1: Complete data set of the websites that were identified and analyzed. Websites for engineering education for the seven languages studied.

\section{Abbreviations}

OER: Open educational resources; PreK-12: Prekindergarten through 12th grade; STEAM: Science, technology, engineering, arts, and math;

STEM: Science, technology, engineering, and math.

\section{Competing interests}

One of the curricula mentioned in the study as an example (the Puppeteering to Engineering Curriculum) has been developed by the first author, Dr. Aikaterini Bagiati, as her doctoral study under the supervision of Dr. Demetra Evangelou.

\section{Authors' contributions}

$A B$ conceived the study, participated in its design and coordination, and helped to draft and revise the manuscript. She also worked on data collection, analysis, and interpretation of the English and Greek resources. SY helped to draft and revise the manuscript. She also worked on data collection, analysis, and interpretation of the Korean resources. DE conceived the study, participated in its design and coordination, and helped to draft and revise the manuscript. AM helped to draft and revise the manuscript. She also worked on data collection, analysis, and interpretation of the Spanish resources. GK helped to draft and revise the manuscript. She also worked on data collection, analysis, and interpretation of the French resources. JZ helped to draft and revise the manuscript. She also worked on data collection, analysis, and interpretation of the Chinese resources. All authors read and approved the final manuscript. 


\section{Author details}

${ }^{1}$ MIT-SUTD Collaboration Office, Massachusetts Institute of Technology, Cambridge, MA, 02139, USA. ${ }^{2}$ Texas A\&M Engineering Experiment Station, Texas A\&M University, College Station, TX 77843, USA. ${ }^{3}$ Department of Education Sciences in Early Childhood, Democritus University, Alexandroupolis 69100, Greece. ${ }^{4}$ Computer and Information Technology Department, Purdue University, West Lafayette, IN 47907, USA. ${ }^{5}$ Department of Education, Lebanese American University, Beirut, Lebanon. ${ }^{6}$ Graduate School of Education, Shanghai Jiao Tong University, Shanghai City, P. R. China.

Received: 27 March 2014 Accepted: 13 December 2014

Published online: 15 January 2015

\section{References}

American Association of Colleges for Teacher Education. (2013). The changing teacher preparation profession: a report from AACTE's professional educational data system (PEDS). http://blogs.edweek.org/edweek/charterschoice/AACTE. pdf. Accessed March 222014.

Bagiati, A. (2011). Early engineering: a developmentally appropriate curriculum for young children (Dissertation). West Lafayette: Purdue University.

Bagiati, A, \& Evangelou, D. (2008). An examination of web-based P-12 engineering curricula: issues of pedagogical and engineering content fidelity. In Proceedings of the Research in Engineering Education Symposium.

Bagiati, A, Evangelou, D (in press (a)). Engineering curriculum in the preschool classroom: the teacher's experience. European Early Childhood Education Research Journal, 23(1).

Bagiati, A, Evangelou, D, (in press (b)) Practicing engineering while building with blocks: identifying engineering thinking. European Early Childhood Education Research Journal, 24(1).

Bagiati, A, Yoon, SY, Evangelou, D, Kaloustian, G, Cekic, O, Zhu, J Magana, AJ (2011). Engineering in early education: A multicultural comparison of web resources. Proceedings of the American Society for Engineering Education Annual Conference, Vancouver, BC, Canada.

Bagiati, A, Yoon, SY, Evangelou, D, \& Ngambeki, I. (2010). Engineering curricula in early education: Describing the landscape of open resources. Early Childhood Research \& Practice, 12(2), 1-15

Bairaktarova, D, Evangelou, D, Bagiati, A, \& Dobbs-Oates, J (2012). The role of classroom artifacts in developmental engineering. In Proceedings of the American Society for Engineering Education Annual Conference, San Antonio, TX.

Becker, SB. (2010). Why don't young people want to become engineers? Rational reasons for disappointing decisions. European Journal of Engineering Education, 35(4), 349-366.

Borko, H, Whitcomb, J, \& Liston, D. (2009). Wicked problems and other thoughts on issues of technology and teacher learning. Journal of Teacher Education, 60(1), 3-7.

Brophy, S \& Evangelou, D (2007). Precursors to engineering thinking (PET). In Proceedings of the American Society for Engineering Education Annual Conference. Honolulu, Hawaii. June 24-27.

Brophy, S, Klein, S, Portsmore, M, \& Rogers, C. (2008). Advancing engineering education in P-12 classrooms. Journal of Engineering Education, 97(3), 369-387.

Bybee, RW. (2011). K-12 engineering education standards: opportunities and barriers. Technology and Engineering Teacher, 70(5), 21-29.

Campos, BP, Kallos, D, \& Stephenson, J. (2000). Green paper on teacher education in Europe. Urnéa, Sweden: TNTEE.

Copple, C, \& Bredekamp, S (Eds.). (2009). Developmentally appropriate practice in early childhood programs serving children from birth through age 8 (3rd ed.). Washington, DC: National Association for Education of Young Children.

Dimopoulos, C, Katzis, K, \& Hawwash, K. (2011). Attracting students to engineering education studies: a survey of practices. Lisbon, Portugal: European Society for Engineering Education (SEFI).

Giordan, A. (2010). Nouveaux contenus, nouvelles pratiques, peut-on mutualiser les problèmes et les acquis? In A. Hasni, \& J. Lebeaume (Éds). Nouveaux enjeux de l'éducation scientifique et technologique: visées, contenus, compétences et pratiques (pp. 17-49). Ottawa : Presses Universitaires.

Gounari, P. (2009). Rethinking critical literacy in the new information age. Critical Inquiry in Language Studies, 6(3), 148-175.

Graziano, WG, Habashi, MM, Evangelou, D, \& Ngambeki, I. (2012). Orientations and motivations: are you a "people person", a "thing person", or both? Motivation and Emotion, 36(4), 465-477.
Hedtke, R, Kahlert, J, \& Schwier, V. (2001). Service industry for teachers? Using the Internet to plan lessons. European journal of education, 36(2), 189-193.

Hsu, M-C, Purzer, S, \& Cardella, ME. (2011). Elementary teachers' views about teaching design, engineering, and technology. Journal of Pre-College Engineering Education Research (J-PEER), 1(2), 31-39.

Johnstone, S. (2005). Open educational resources serve the world. Sharing educational resources over the Internet provides multiple benefits, from academic collaboration to economic development. Boulder, Colorado: EDUCAUSE Quarterly.

Jung, I. (2005). ICT-pedagogy integration in teacher training: application cases worldwide. Educational Technology \& Society, 8(2), 94-101.

Katehi, L, Pearson, G, \& Feder, M. (2009). The status and nature of K-12 engineering education in the United States. The Bridge, 3(3), 5-10.

Kim, KS, Hong, JH, Huh, CS, Moon, DY, Kim, MY, Lee, CH, Kim, KY, Choi, EK, \& Kim, YM. (2013). A study on the reinforcement strategies of engineering education in elementary and secondary school [초중등 공학교육 강화방안 정책연구]. Daejeon, South Korea: Korea Ministry of Education, Science, and Technology [한국교육과학기술부], Korea Foundation for the Advancement of Science \& Creativity [한국과학창의재단].

Kuenzi, JJ. (2008). CRS report for congress: science, technology, engineering, and mathematics (STEM) education: background, federal policy, and legislative action. Congressional Research Service, Library of Congress, RL33434, Washington, DC. Retrieved on December $30^{\text {th }} 2014$ from https://www.hsdl.org/? view\&did=715973

Lebeaume, J. (2011). Integration of Science, Technology, Engineering and Mathematics: Is This Curricular Revolution Really Possible in France? Design and Technology Education, 16(1), 47-52.

Lock, JV. (2006). A new image: online communities to facilitate teacher professional development. Journal of Technology and Teacher Education, 14(4), 663-678.

Moore, TJ. (2010). Implementing K-12 engineering standards through STEM integration. In National Science Foundation (NSF) Faculty Early Career Development (CAREER) Program, Engineering Education Division, Award \# 1055382.

National Research Council. (2009). Engineering in K-12 education: understanding the status and improving the prospects. Washington, DC: The National Academies Press.

Perrault, AM (2007). An exploratory study of biology teachers' online information seeking practices. School Library Media Research (pp. 10).

Pimienta, D, Prado, D, \& Blanco, A. (2009). Twelve years of measuring linguistic diversity in the Internet: balance and perspectives. Paris: United Nations Educational, Scientific and Cultural Organization.

Punie, Y. (2012). Preface. In Joint Research Centre of the European Commission Innovating Learning: key elements for developing creative classroom in Europe (p. 1). Luxemburg: Publications Office of the European Union.

Recker, M. (2006). Perspectives on teachers as digital library users: consumers, contributors, and designers. D-Lib Magazine, 12(9), 2.

Recker, M, Dorward, J, \& Nelson, LM. (2004). Discovery and use of online learning resources: case study findings. Journal of Educational Technology and Society, 7, 93-104.

Sanders, M. (2009). STEM, STEM education, STEMmania. The Technology Teacher, 20, 20-26.

Shulman, LS. (1986). Those who understand: knowledge growth in teaching Educational Researcher, 15(2), 4-14.

Toombs, WE, \& Tierney, WG. (1993). Curriculum definitions and reference points. Journal of Curriculum and Supervision, 8(3), 175-195. Retrieved from http:// www.ascd.org/publications/jcs/spring1993/Curriculum-Definitions-andReference-Points.aspx.

Wang, H-H, Moore Tamara, J, Roehrig, GH, \& Park, MS. (2011). STEM integration: teacher perceptions and practice. Journal of Pre-College Engineering Education Research, 1, 2

Watt, HM, Richardson, PW, \& Pietsch, J. (2007). Choosing to teach in the "STEM" disciplines: characteristics and motivations of science, ICT, and mathematics teachers. In mathematics: essential research, essential practice. In Proceedings of the 30th Annual Conference of the Mathematics Education Research Group of Australasia (2nd ed., pp. 795-804). Adelaide: MERGA.

Wiggins, G, \& McTighe, J. (1997). Understanding by design. Alexandria, VA: Association for Supervision and Curriculum Development.

Wiggins, G, \& McTighe, J. (2005). Understanding by design (2nd ed.). San Francisco, CA: Pearson Education.

Yaşar, Ş, Baker, D, Robinson-Kurpius, S, Krause, S, \& Roberts, C. (2006). Development of a survey to assess K-12 teachers' perceptions of engineers and familiarity with teaching design, engineering, and technology. Journal of Engineering Education, 95(3), 205-216. 